\title{
Using Google Glass in Nonsurgical Medical Settings: Systematic Review
}

\author{
Bryn Dougherty ${ }^{1}$, BS; Sherif M Badawy ${ }^{2,3,4}$, MD, MS, MBBCh \\ ${ }^{1}$ Northwestern University Weinberg College of Arts and Sciences, Evanston, IL, United States \\ ${ }^{2}$ Division of Hematology, Oncology and Stem Cell Transplantation, Ann \& Robert H. Lurie Children's Hospital of Chicago, Chicago, IL, United States \\ ${ }^{3}$ Department of Pediatrics, Northwestern University Feinberg School of Medicine, Chicago, IL, United States \\ ${ }^{4}$ Department of Pediatrics, Division of Hematology and Oncology, Zagazig University Faculty of Medicine, Zagazig, Egypt
}

\section{Corresponding Author:}

Sherif M Badawy, MD, MS, MBBCh

Division of Hematology, Oncology and Stem Cell Transplantation

Ann \& Robert H. Lurie Children's Hospital of Chicago

225 E. Chicago Ave, Box \#30

Chicago, IL, 60611

United States

Phone: 13122274836

Fax: 13122279376

Email: sbadawy@luriechildrens.org

\begin{abstract}
Background: Wearable technologies provide users hands-free access to computer functions and are becoming increasingly popular on both the consumer market and in various industries. The medical industry has pioneered research and implementation of head-mounted wearable devices, such as Google Glass. Most of this research has focused on surgical interventions; however, other medical fields have begun to explore the potential of this technology to support both patients and clinicians.
\end{abstract}

Objective: Our aim was to systematically evaluate the feasibility, usability, and acceptability of using Google Glass in nonsurgical medical settings and to determine the benefits, limitations, and future directions of its application.

Methods: This review covers literature published between January 2013 and May 2017. Searches included PubMed MEDLINE, Embase, INSPEC (Ebsco), Cochrane Central Register of Controlled Trials (CENTRAL), IEEE Explore, Web of Science, Scopus, and Compendex. The search strategy sought all articles on Google Glass. Two reviewers independently screened titles and abstracts, assessed full-text articles, and extracted data from articles that met all predefined criteria. Any disagreements were resolved by discussion or consultation by the senior author. Included studies were original research articles that evaluated the feasibility, usability, or acceptability of Google Glass in nonsurgical medical settings. The preferred reporting results of systematic reviews and meta-analyses (PRISMA) guidelines were followed for reporting of results.

Results: Of the 852 records examined, 51 met all predefined criteria, including patient-centered $(\mathrm{n}=21)$ and clinician-centered studies $(\mathrm{n}=30)$. Patient-centered studies explored the utility of Google Glass in supporting patients with motor impairments $(\mathrm{n}=8)$, visual impairments $(n=5)$, developmental and psychiatric disorders $(n=2)$, weight management concerns $(n=3)$, allergies $(n=1)$, or other health concerns $(n=2)$. Clinician-centered studies explored the utility of Google Glass in student training ( $n=9)$, disaster relief $(n=4)$, diagnostics $(n=2)$, nursing $(n=1)$, autopsy and postmortem examination $(n=1)$, wound care $(n=1)$, behavioral sciences $(n=1)$, and various medical subspecialties, including, cardiology $(n=3)$, radiology $(n=3)$, neurology $(n=1)$, anesthesiology $(n=1)$, pulmonology $(n=1)$, toxicology $(n=1)$, and dermatology $(n=1)$. Most of the studies were conducted in the United States $(40 / 51$, $78 \%$ ), did not report specific age information for participants $(38 / 51,75 \%)$, had sample size <30 participants $(29 / 51,57 \%)$, and were pilot or feasibility studies $(31 / 51,61 \%)$. Most patient-centered studies $(19 / 21,90 \%)$ demonstrated feasibility with high satisfaction and acceptability among participants, despite a few technical challenges with the device. A number of clinician-centered studies $(11 / 30,37 \%)$ reported low to moderate satisfaction among participants, with the most promising results being in the area of student training. Studies varied in sample size, approach for implementation of Google Glass, and outcomes assessment.

Conclusions: The use of Google Glass in nonsurgical medical settings varied. More promising results regarding the feasibility, usability, and acceptability of using Google Glass were seen in patient-centered studies and student training settings. Further 
research evaluating the efficacy and cost-effectiveness of Google Glass as an intervention to improve important clinical outcomes is warranted.

(JMIR Mhealth Uhealth 2017;5(10):e159) doi: 10.2196/mhealth.8671

\section{KEYWORDS}

Google Glass; wearable; wearable device; head-mounted wearable device; non-surgical setting; non-surgical condition; medical setting; medical condition

\section{Introduction}

Wearable technology is defined as any compact device, either in the form of a body sensor or head-mounted display, which provides a user information and allows user interaction via voice command or physical input [1]. The purpose of these devices is to create convenient, portable, and hands-free access to computers, thus facilitating or enhancing everyday tasks. Many of these devices can perform the same functions as mobile phones and laptop computers, while also outperforming them with their sensory and scanning abilities [2]. Google Glass (Google, Inc.), often referred to as "Glass," which resembles standard eyeglasses, is one of the more well-known devices in this emerging field since its release in 2013 [3].

Google Glass has distinguished itself from other head-mounted or heads-up wearable devices by providing users with a comfortable, unobtrusive, wireless platform that runs the Android operating system and displays virtual or augmented reality with little obstruction to normal vision [3]. While it has not yet seen much success in the consumer market, various industries have taken an interest in the potential applications of a head-mounted, ubiquitous computer that could be used for a range of tasks, including recording and streaming videos, data transmission, telementoring in education, and teleconferences for professional collaboration [3]. Health care is one such industry that has pioneered research investigating how Google Glass could be leveraged to support both clinicians and patients.

Surgeons were among the first in the medical industry to incorporate Google Glass into their work. As a hands-free device that can react to voice commands, eye movements, and simple gestures, it is particularly attractive in environments where both hands are generally occupied with surgical tasks and maintaining sterility is of upmost importance [4]. In a recent systematic review, Davis and Rosenfield reported an overall positive impact of using Google Glass in surgical settings with data to support the feasibility and acceptability of its use for medical care, surgical skills training, medical documentation, and patient safety [4]. Many other specialties in medicine have followed the lead of the surgical field and conducted their own studies to assess the feasibility of using Google Glass in nonsurgical medical settings.

While Google Glass is an exciting technology with a number of promising applications in medicine, it remains unclear which applications are most worth pursuing, what potential limitations are associated with its use, and the extent to which patients and clinicians might benefit from its use. The objectives of this review are to systematically evaluate the most recent evidence for the feasibility, usability, and acceptability of using Google
Glass in nonsurgical settings, and determine its potential benefits, limitations, and future directions in these settings.

\section{Methods}

We followed the guidelines for the Preferred Reporting Items for Systematic Reviews and Meta-Analyses (PRISMA) in the reporting of evidence across the studies we reviewed (Multimedia Appendix 1) [5].

\section{Article Retrieval}

A librarian collaboratively developed the search strategies with the senior author (SB) and ran searches in the following databases in November 2015: PubMed MEDLINE, Embase, INSPEC (Ebsco), Cochrane Central Register of Controlled Trials (CENTRAL) on the Wiley platform, IEEE Explore, Web of Science, Scopus, and Compendex. An updated search of all databases was run in January 2017 to look for additional articles. Search strategies for all databases except MEDLINE were adapted from the PubMed MEDLINE strategy. All databases were searched back to 2013, when Google Glass was first released. No language limits were applied. The search strategy specified keywords related to Google Glass. We also reviewed the search strategies of previous studies to include additional terms. See Multimedia Appendix 2 for complete search strategies in each database. An additional hand-search of related themes in the Journal of Medical Internet Research was also conducted. We also attempted to identify additional studies by searching the reference lists of key studies and relevant systematic reviews.

\section{Study Selection}

The inclusion criteria were as follows: (1) original research articles, (2) studies that were either randomized controlled trials, quasi-experimental studies, or pilot/feasibility studies (including single arm, pre-posttest), (3) Google Glass interventions, (4) nonsurgical study settings, and (5) clinical, usability, feasibility, and/or acceptability as primary or secondary outcome. The exclusion criteria included (1) technology-based interventions other than Google Glass, (2) surgical study settings, and (3) articles with more technical description of Google Glass but no clinical, usability, feasibility, and/or acceptability outcomes.

\section{Data Extraction and Analysis}

We used a standardized form for data extraction. Data items in the extraction form included the following: first author's name, publication year, country, condition or disease focus of the study, purpose of the study, description of how Google Glass was used in the study as an intervention, participants' age (when available), study design, study setting, duration of the study, and other study considerations. Two authors coded all included 
articles individually. Disagreements were resolved by discussion or by consultation with the senior author (SB), if needed. Quantitative and qualitative data analyses were conducted.

\section{Results}

\section{Literature Search}

The literature search identified 852 references (Figure 1), and 498 individual full articles were retrieved. A total of 51 articles met all inclusion criteria. Some of the interventions (21/51, $41 \%$ ) studied the potential of Google Glass in aiding patients with a variety of conditions [6-26], while the majority (30/51, $59 \%$ ) studied its potential uses in assisting health care professionals in their work [27-56]. The patient-focused studies aimed to help individuals with motor impairments $(8 / 21,38 \%)$ [6-13], visual impairments $(5 / 21,24 \%)$ [14-18], developmental and psychiatric disorders $(2 / 21,9 \%)$ [19,20], weight management concerns $(3 / 21,14 \%)$ [21-23], allergies $(1 / 21,5 \%)$ [26], or other health concerns leading them to track specific physiological metrics $(2 / 21,10 \%)[24,25]$. The clinician-focused studies analyzed Google Glass use in student training $(9 / 30$, $30 \%)[35,37,38,40,41,46,48,49,52]$, disaster relief $(4 / 30,13 \%)$ [27-30], diagnostics $(2 / 30,7 \%)$ [32,50], nursing $(1 / 30,3 \%)$ [33], autopsy and postmortem examination (1/30, 3\%) [53], wound care $(1 / 30,3 \%)$ [54], behavioral sciences $(1 / 30,3 \%)$ [31], and various medical specialties, including cardiology (3/30, $10 \%$ ) [43-45], radiology $(3 / 30,10 \%)[39,42,47]$, neurology $(1 / 30,3 \%)$ [34], anesthesiology $(1 / 30,3 \%)$ [36], pulmonology $(1 / 30,3 \%)$ [51], toxicology $(1 / 30,3 \%)$ [55], and dermatology $(1 / 30,3 \%)$ [56].

\section{Description of Included Studies}

Tables 1 and 2 summarize the characteristics of patient- and clinician-centered studies, respectively. In total, 40 studies were conducted in the United States [6-9,13-18,20-24,27,29,31, $32,35,37-41,43-52,54-57]$, three in Germany [25,26,53], two in
United Kingdom [10,11], China [34,36], and one each in Australia [33], Switzerland [42], Mexico [19], Netherlands [12], Norway [30], and Italy [28]. Less than half of the included studies $(19 / 51,37 \%)$ were conducted in a laboratory setting $[6-9,12,14,16-19,21-24,27,31,33,42,50], 13(25 \%)$ in a hospital setting [32,34,36,38,39,43,44,46,51,53-56], seven (14\%) in a classroom or clinical student training setting [35,37, $40,41,47,48,52]$, three in patient residences $(6 \%)[13,15,20]$, three in local settings (6\%) [28-30], and one in a dental office (2\%) [49]. The remaining five studies were conducted in varying locations (10\%) [10,11,25,26,45]. There was significant variability in information reported about participant demographics. Most $(n=38)$ did not report any specific age information for participants [7,8,13-15,19-21,26-52,54-56], but none of these were conducted in pediatric settings. Of the 13 studies that did report participant age information, seven enrolled young adults (average age or age range $\leq 35$ years) $[6,18,22-25,53]$, three enrolled adults (average age or age range $>36$ and $<60$ years) $[9,16,17]$, two enrolled older adults (average age or age range $\geq 60$ years) $[10,12]$ and one study reported an age range of 46-70 years [11]. Sample size ranged from 1-106 participants, with a median of 12 and a mean of 22 participants per study; 29 enrolled <30 [6,7,9-14,16-21,23-27, $30,38-40,43-45,48,53,54]$ and 10 had $\geq 30$ participants $[22,31,33,36,37,41,47,49,52,56]$. Some of the studies $(12 / 51$, $23.5 \%$ ) did not report the number of participants $[8,15,28,29,32,34,35,42,46,50,51,55]$. None of the studies reported information about participants' race and ethnicity. Most (31/51, 61\%) were pilot or feasibility studies [6-16,18,20-22, 24,26-29,32,33,35,36,38,47,48,53-56], six were randomized controlled trials $(6 / 51,12 \%)$ [30,31,37,40,41,52], five were exploratory studies $(5 / 51,10 \%)[42,44,45,49,50]$, five were case studies $(5 / 51,10 \%)[17,23,34,46,51]$, and four were quasi-experimental $(4 / 51,8 \%)[19,25,39,43]$. None of the studies included any follow-up with participants after completion of the intervention. 
Table 1. Summary of studies using Google Glass as patient-centered interventions.

\begin{tabular}{|c|c|c|c|c|}
\hline Source (country) & Health condition & Study design & Study setting & Google Glass (GG) use \\
\hline $\begin{array}{l}\text { Anam et al, } 2014 \\
\text { (United States) }\end{array}$ & $\begin{array}{l}\text { Ophthalmology - visual } \\
\text { impairment }\end{array}$ & $\begin{array}{l}\text { Pilot/feasibility } \\
\text { study }\end{array}$ & Laboratory & Monitors and reports nonverbal social cues to user \\
\hline $\begin{array}{l}\text { Garcia and Nahapetian, } \\
2015 \\
\text { (United States) }\end{array}$ & $\begin{array}{l}\text { Ophthalmology - visual } \\
\text { impairment }\end{array}$ & $\begin{array}{l}\text { Pilot/feasibility } \\
\text { study }\end{array}$ & Patient home & $\begin{array}{l}\text { Analyzes environment and reports the information } \\
\text { to user to help them navigate a room }\end{array}$ \\
\hline $\begin{array}{l}\text { Pundlik et al, } 2016 \\
\text { (United States) }\end{array}$ & $\begin{array}{l}\text { Ophthalmology - visual } \\
\text { impairment }\end{array}$ & $\begin{array}{l}\text { Pilot/feasibility } \\
\text { study }\end{array}$ & Laboratory & $\begin{array}{l}\text { Magnifies user's vision while completing a series of } \\
\text { tasks }\end{array}$ \\
\hline $\begin{array}{l}\text { Hwang and Peli, } 2016 \\
\text { (United States) }\end{array}$ & $\begin{array}{l}\text { Ophthalmology - ad- } \\
\text { vanced age-related macu- } \\
\text { lar degeneration }\end{array}$ & Case study & Laboratory & $\begin{array}{l}\text { Warps the vision of participants in efforts to improve } \\
\text { vision }\end{array}$ \\
\hline $\begin{array}{l}\text { Tanuwidjaja et al, } 2014 \\
\text { (United States) }\end{array}$ & $\begin{array}{l}\text { Ophthalmology - color- } \\
\text { blindness }\end{array}$ & $\begin{array}{l}\text { Pilot/feasibility } \\
\text { study }\end{array}$ & Laboratory & Helps participants identify colors \\
\hline $\begin{array}{l}\text { Lazewatsky et al, } 2014 \\
\text { (United States) }\end{array}$ & Motor impairment & $\begin{array}{l}\text { Pilot/feasibility } \\
\text { study }\end{array}$ & Laboratory & Helps participants guide the robot personal assistant \\
\hline $\begin{array}{l}\text { Gips et al, } 2015 \\
\text { (United States) }\end{array}$ & Motor impairment & $\begin{array}{l}\text { Pilot/feasibility } \\
\text { study }\end{array}$ & Laboratory & $\begin{array}{l}\text { Allows people to operate a computer with only eye } \\
\text { or head movements }\end{array}$ \\
\hline $\begin{array}{l}\text { Sinyukov et al, } 2016 \\
\text { (United States) }\end{array}$ & $\begin{array}{l}\text { Motor impairment - } \\
\text { Locked-In Syndrome }\end{array}$ & $\begin{array}{l}\text { Pilot/feasibility } \\
\text { study }\end{array}$ & Laboratory & $\begin{array}{l}\text { Uses voice control function of GG to allow people } \\
\text { to navigate an electric wheelchair in indoor environ- } \\
\text { ments }\end{array}$ \\
\hline $\begin{array}{l}\text { Malu and Findlater, } 2015 \\
\text { (United States) }\end{array}$ & $\begin{array}{l}\text { Motor impairment - up- } \\
\text { per body impairment }\end{array}$ & $\begin{array}{l}\text { Pilot/feasibility } \\
\text { study }\end{array}$ & Laboratory & $\begin{array}{l}\text { Uses touchpad and visual display to perform tasks } \\
\text { on a computer/ mobile phone }\end{array}$ \\
\hline $\begin{array}{l}\text { McNaney et al, } 2014 \\
\text { (United Kingdom) }\end{array}$ & $\begin{array}{l}\text { Motor impairment - } \\
\text { Parkinson's Disease }\end{array}$ & $\begin{array}{l}\text { Pilot/feasibility } \\
\text { study }\end{array}$ & $\begin{array}{l}\text { Varying locations (pa- } \\
\text { tient home, in public) }\end{array}$ & Helps in daily interactions and common activities \\
\hline $\begin{array}{l}\text { McNaney et al, } 2015 \\
\text { (United Kingdom) }\end{array}$ & $\begin{array}{l}\text { Motor impairment - } \\
\text { Parkinson's Disease }\end{array}$ & $\begin{array}{l}\text { Pilot/feasibility } \\
\text { study }\end{array}$ & $\begin{array}{l}\text { Varying locations (pa- } \\
\text { tient home, in public) }\end{array}$ & $\begin{array}{l}\text { Monitors user's speech volume and provides feed- } \\
\text { back }\end{array}$ \\
\hline $\begin{array}{l}\text { Zhao et al, } 2016 \\
\text { (Netherlands) }\end{array}$ & $\begin{array}{l}\text { Motor impairment - } \\
\text { Parkinson's Disease }\end{array}$ & $\begin{array}{l}\text { Pilot/feasibility } \\
\text { study }\end{array}$ & Laboratory & Provides visual and auditory cues to modulate gait \\
\hline $\begin{array}{l}\text { Pervaiz and Patel, } 2014 \\
\text { (United States) }\end{array}$ & $\begin{array}{l}\text { Motor impairment - } \\
\text { Dysarthria }\end{array}$ & $\begin{array}{l}\text { Pilot/feasibility } \\
\text { study }\end{array}$ & Assisted living facility & $\begin{array}{l}\text { Helps people be aware of their volume, notifies them } \\
\text { when to raise it, and provides feedback to clinicians } \\
\text { so they can adjust therapy }\end{array}$ \\
\hline $\begin{array}{l}\text { Miranda et al, } 2014 \\
\text { (Mexico) }\end{array}$ & $\begin{array}{l}\text { Psychiatric/Developmen- } \\
\text { tal - Social Anxiety Dis- } \\
\text { order (SAD) }\end{array}$ & $\begin{array}{l}\text { Quasi-experi- } \\
\text { mental }\end{array}$ & Laboratory & Monitors symptoms of SAD through blinking habits \\
\hline $\begin{array}{l}\text { Voss et al, } 2016 \\
\text { (United States) }\end{array}$ & $\begin{array}{l}\text { Psychiatric/Developmen- } \\
\text { tal - Children with } \\
\text { Autism Spectrum Disor- } \\
\text { der (ASD) }\end{array}$ & $\begin{array}{l}\text { Pilot/feasibility } \\
\text { study }\end{array}$ & Patient home & Uses the video feature to monitor everyday life \\
\hline $\begin{array}{l}\text { Mirtchouk et al, } 2016 \\
\text { (United States) }\end{array}$ & Eating monitoring & $\begin{array}{l}\text { Pilot/feasibility } \\
\text { study }\end{array}$ & Laboratory & Records head motion while participants eat \\
\hline $\begin{array}{l}\text { Rahman et al, } 2015 \\
\text { (United States) }\end{array}$ & Eating monitoring & $\begin{array}{l}\text { Pilot/feasibility } \\
\text { study }\end{array}$ & Laboratory & $\begin{array}{l}\text { Records user's eating and drinking habits through } \\
\text { head movements }\end{array}$ \\
\hline $\begin{array}{l}\text { Ye et al, } 2015 \\
\text { (United States) }\end{array}$ & Eating monitoring & Case study & Laboratory & Records head motion while participants eat \\
\hline $\begin{array}{l}\text { Hernandez et al, } 2014 \\
\text { (United States) }\end{array}$ & $\begin{array}{l}\text { Physiological measure- } \\
\text { ments }\end{array}$ & $\begin{array}{l}\text { Pilot/feasibility } \\
\text { study }\end{array}$ & Laboratory & $\begin{array}{l}\text { The accelerometer, gyroscope, and camera on GG } \\
\text { are used to analyze the heart and respiration rate of } \\
\text { user wearing the device }\end{array}$ \\
\hline $\begin{array}{l}\text { Richer et al, } 2015 \\
\text { (Germany) }\end{array}$ & $\begin{array}{l}\text { Physiological measure- } \\
\text { ments }\end{array}$ & $\begin{array}{l}\text { Quasi-experi- } \\
\text { mental study }\end{array}$ & $\begin{array}{l}\text { Varying locations (pa- } \\
\text { tients' everyday lives) }\end{array}$ & $\begin{array}{l}\text { Serves as the "wearable extension" portion of the } \\
\text { DailyHeart app }\end{array}$ \\
\hline
\end{tabular}




\begin{tabular}{lllll}
\hline Source (country) & Health condition & Study design & Study setting & Google Glass (GG) use \\
\hline $\begin{array}{l}\text { Wiesner et al, 2015 } \\
\text { (Germany) }\end{array}$ & Allergies & $\begin{array}{l}\text { Pilot/feasibility } \\
\text { study }\end{array}$ & $\begin{array}{l}\text { Varying locations } \\
\text { (drugstores selling } \\
\text { cosmetic products) }\end{array}$ & $\begin{array}{l}\text { Cross checks ingredients on cosmetic product pack- } \\
\text { age with a list of allergens created by the user in their } \\
\text { online profile }\end{array}$ \\
\hline
\end{tabular}

\section{Description of Google Glass Use as Patient-Centered Interventions}

Table 3 summarizes the Google Glass approach as patient-centered interventions. Five of the studies $(5 / 21,24 \%)$ used Google Glass to assist individuals with visual impairments or in low vision environments by providing them information about nonverbal social cues [14], allowing them to better navigate environments with the use of floor plans [15], improving vision magnification using mobile phone zoom capabilities [16], compensating for age-related vision impairments [17], and augmenting color perception [18]. Eight studies $(8 / 21,38 \%)$ using Google Glass to help individuals with various motor impairments provided them with an accessible interface to control an assistive robot [6] or an electric wheelchair [8]. This allowed them to operate a computer using only head or eye movements [7], facilitating everyday tasks with the use of voice commands and the touchpad [9], managing symptoms of Parkinson's Disease (PD) [10-12], and providing speech feedback to patients with dysarthria to allow them to better adjust their volume [13]. Two studies $(2 / 21,10 \%)$ used Google Glass to help individuals with psychiatric or developmental disorders by recording blinking information as an indication of anxiety experienced by those with social anxiety disorder (SAD) [19] and by recording behaviors of individuals with autistic spectrum disorder (ASD) to provide better information to caregivers and clinicians [20]. Three studies $(3 / 21,14 \%)$ used Google Glass to assist in weight management by detecting and recording a person's eating and drinking habits [21-23]. Two studies $(2 / 21,10 \%)$ provided individuals with real-time electrocardiograms (ECG) [25] or other physiological measurement feedback [24]. Finally, one study $(1 / 21,5 \%)$ allowed users to scan the ingredients of cosmetic products in drug stores to filter for common allergens [26].

Figure 1. Flow of studies according to PRISMA guidelines.
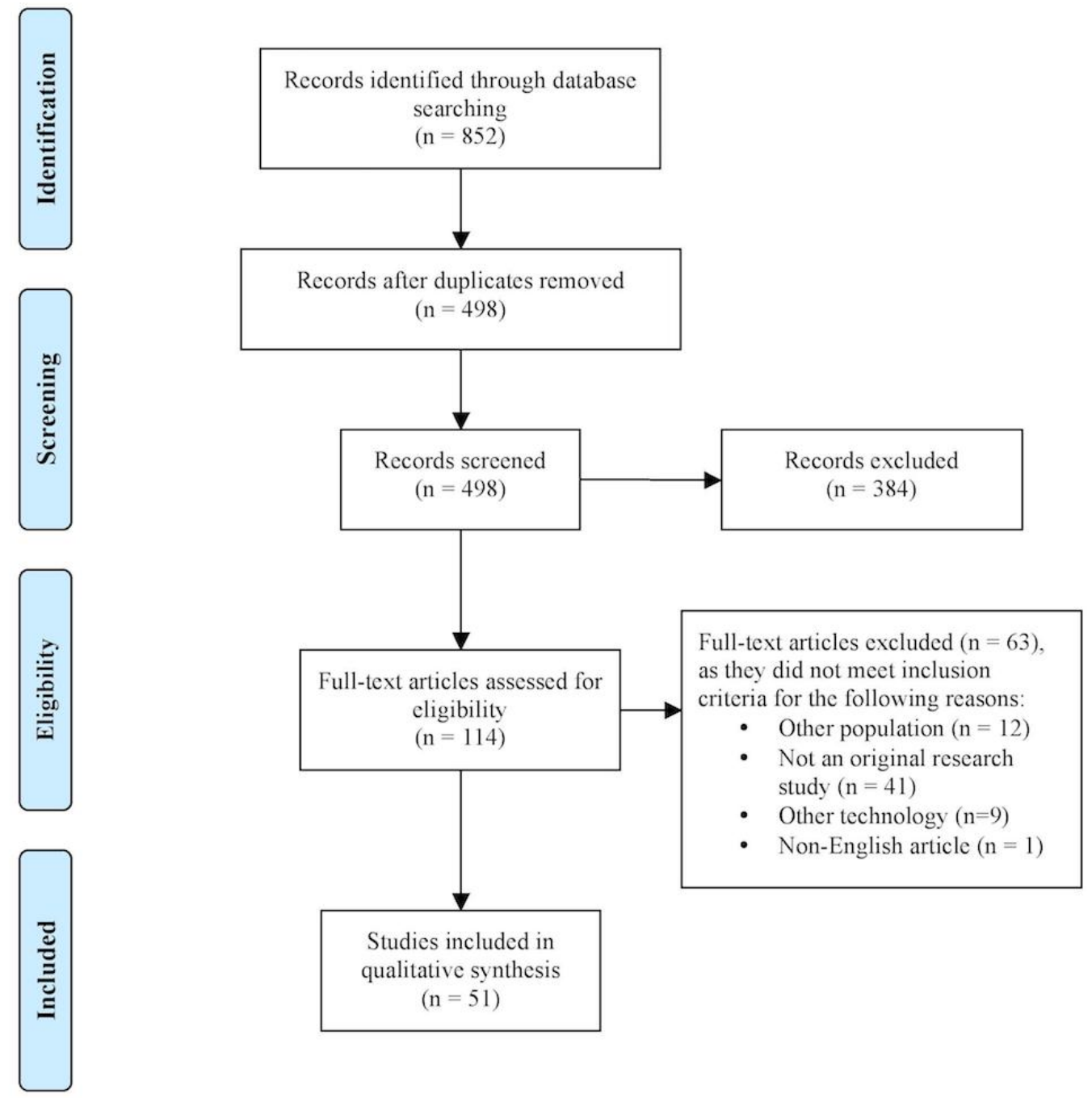
Table 2. Summary of studies using Google Glass as clinician-focused interventions.

\begin{tabular}{|c|c|c|c|c|}
\hline Source (country) & Health condition & Study design & Study setting & Google Glass (GG) use \\
\hline $\begin{array}{l}\text { Gillis et al, } 2015 \\
\text { (United States) }\end{array}$ & Disaster relief & Pilot/feasibility study & Laboratory & $\begin{array}{l}\text { Allows for audiovisual communication with } \\
\text { each group of paramedics and the adminis- } \\
\text { trator; the virtual beacon component is used } \\
\text { to eliminate the use for paper triage tags }\end{array}$ \\
\hline
\end{tabular}

Carenzo et al, $2014 \quad$ Disaster relief Pilot/feasibility study

(Italy)

Cicero et al, 2014

(United States)

Disaster relief

Pilot/feasibility study

Newaz and Eide, 2015 Disaster relief

(Norway)

Paxton et al, 2015

Behavioral sciences

(United States)

Pappachan et al, $2014 \quad$ Diagnostics

(United States)

Pascale et al, 2015

(Australia)

Yuan et al, 2015

(China)

Chaballout et al, 2016

(United States)

Drake-Brockman et al, Anesthesiology

2016

(China)

Iversen et al, 2016

(United States)

Son et al, 2015

(United States)

Spaedy et al, 2016

(United States)

Russel et al, 2014

(United States)

Wu et al, 2014

(United States)

Widmer et al, 2014

(Switzerland)

Stetler et al, 2015

(United States)

Duong et al, 2015

(United States)

Student training - medi-
Nursing - Peripheral de- Pilot/feasibility study Laboratory tection

Neurology

Case study

Student training - health Pilot/feasibility study science students

Pilot/feasibility study

Student training - physiotherapy students

Student training - otolaryngology residents

Radiology cal students (radiology)

Randomized controlled trial

Student training - medi- Randomized controlled cal students and radiolo- trial gy residents

Dermatology and Radiol- Exploratory study ogy

Cardiology

Quasi-experimental

Cardiology

Exploratory study ty) ology ogy

Medicine)

Laboratory
Local - Field hospital Scans triage tags to provide their information, timestamp, and Global Positioning System (GPS) coordinates and relay the information back to the hospital

Facilitates communication with telemedicine physician disaster expert who can confirm the triage decision of the intervention team, and determines time of triage for each patient

Provides navigation and maps to first responders

Uses PsyGlass app to facilitate the use of GG in behavioral, cognitive, and social research

Hospital-Emergency Helps community health workers to identify department certain disorders based on the patient demographics

Improves detection in the periphery

Hospital - Neurology Facilitates communication between physicians during a neurological examination

Classroom (universi- Presents a simulation in conjunction with real time performance of treatment on a manikin

Hospital - Anesthesi- Uses heads-up display to facilitate monitoring patient vitals while performing procedures

Classroom (large, pri- Captures 1st-person view of a procedure vate, non-profit research university) and displays it for learning purposes

Hospital - Otolaryngol- Uses the video capabilities to record resi-

dent encounters with patients

Hospital - Radiology

Takes images of and displays X-rays for physician interpretation

Instructional testing room (University of Kentucky, School of

Provides live instruction from an expert via Google Hangout

Classroom (University Facilitates procedures by showing real-time of Arizona College of ultrasound images on the heads-up display Medicine - Phoenix)

Takes and analyzes images to facilitate interpretation and diagnostic decisions by presenting similar images to user

Hospital-Cardiology Captures images of the electrocardiogram (ECGs) and presents them on heads-up display to facilitate interpretation

Hospital-Cardiology Records coronary angiograms were recorded to be reviewed on the heads-up display or transferred to a mobile phone 


\begin{tabular}{|c|c|c|c|c|}
\hline Source (country) & Health condition & Study design & Study setting & Google Glass (GG) use \\
\hline $\begin{array}{l}\text { Jeroudi et al, } 2014 \\
\text { (United States) }\end{array}$ & Cardiology & Exploratory study & $\begin{array}{l}\text { Remote (location var- } \\
\text { ied by physician re- } \\
\text { viewer) }\end{array}$ & Displays ECG images for interpretation \\
\hline $\begin{array}{l}\text { Vallurupalli et al, } 2013 \\
\text { (United States) }\end{array}$ & $\begin{array}{l}\text { Student training - medi- } \\
\text { cal students (cardiology) }\end{array}$ & Case study & $\begin{array}{l}\text { Hospital - Cardiology } \\
\text { (University of } \\
\text { Arkansas for Medical } \\
\text { Sciences, Division of } \\
\text { Cardiology) }\end{array}$ & $\begin{array}{l}\text { Facilitates collaboration between cardiology } \\
\text { attending and resident in clinical training } \\
\text { settings }\end{array}$ \\
\hline $\begin{array}{l}\text { Benninger, } 2015 \\
\text { (United States) }\end{array}$ & Radiology & Pilot/feasibility study & $\begin{array}{l}\text { Anatomy laboratory } \\
\text { (Medical School) }\end{array}$ & $\begin{array}{l}\text { Displays images captured by an ultrasound } \\
\text { finger probe to teach medical students } \\
\text { anatomy and simple interventions }\end{array}$ \\
\hline $\begin{array}{l}\text { Vaughn et al, } 2016 \\
\text { (United States) }\end{array}$ & $\begin{array}{l}\text { Student training - nurs- } \\
\text { ing students }\end{array}$ & Pilot/feasibility study & $\begin{array}{l}\text { Classroom (Nursing } \\
\text { School) }\end{array}$ & $\begin{array}{l}\text { Presents a simulation in conjunction with } \\
\text { real-time performance of treatment on a } \\
\text { manikin }\end{array}$ \\
\hline $\begin{array}{l}\text { Zahl et al, } 2016 \\
\text { (United States) }\end{array}$ & $\begin{array}{l}\text { Student training - dental } \\
\text { students }\end{array}$ & Exploratory study & Dental office & Records student SP station for later analysis \\
\hline $\begin{array}{l}\text { Feng et al, } 2015 \\
\text { (United States) }\end{array}$ & $\begin{array}{l}\text { Diagnostics - Human } \\
\text { immunodeficiency virus } \\
\text { (HIV) and cancer }\end{array}$ & Exploratory study & Laboratory & $\begin{array}{l}\text { Takes rapid diagnostic tests (RDTs), images } \\
\text { prostate specific antigen (PSA) tests, and } \\
\text { images previously activated free PSA and } \\
\text { total PSA RDTs }\end{array}$ \\
\hline $\begin{array}{l}\text { Spencer et al, } 2014 \\
\text { (United States) }\end{array}$ & $\begin{array}{l}\text { Pulmonology - airway } \\
\text { assessment for burn vic- } \\
\text { tims }\end{array}$ & Case study & $\begin{array}{l}\text { Hospital - Burn unit } \\
\text { (Massachusetts Gener- } \\
\text { al Hospital) }\end{array}$ & $\begin{array}{l}\text { Facilitates assessment and management of } \\
\text { the airway }\end{array}$ \\
\hline $\begin{array}{l}\text { Tully et al, } 2015 \\
\text { (United States) }\end{array}$ & $\begin{array}{l}\text { Student training - medi- } \\
\text { cal students (hospice) }\end{array}$ & $\begin{array}{l}\text { Randomized controlled } \\
\text { trial }\end{array}$ & $\begin{array}{l}\text { University of Arizona, } \\
\text { College of Medicine: } \\
\text { Phoenix and local } \\
\text { hospice organization }\end{array}$ & $\begin{array}{l}\text { Records student standardized patient encoun- } \\
\text { ters for later analysis }\end{array}$ \\
\hline $\begin{array}{l}\text { Aldaz et al, } 2015 \\
\text { (United States) }\end{array}$ & Chronic wounds & Pilot/feasibility study & $\begin{array}{l}\text { Hospital - Wound } \\
\text { care (Stanford Hospi- } \\
\text { tal and Clinics) }\end{array}$ & $\begin{array}{l}\text { Uses SnapCap software to facilitate hands- } \\
\text { free digital imaging and the tagging and } \\
\text { transfer of images to patient's electronic } \\
\text { medical record in chronic wound care assess- } \\
\text { ments }\end{array}$ \\
\hline $\begin{array}{l}\text { Chai et al, } 2015 \\
\text { (United States) }\end{array}$ & Toxicology & Pilot/feasibility study & $\begin{array}{l}\text { Hospital - Emergency } \\
\text { department (urban } \\
\text { academic hospital) }\end{array}$ & $\begin{array}{l}\text { Sends photographs and videos to the toxicol- } \\
\text { ogy supervisors; acts as a platform for in- } \\
\text { struction of } 2 \text { nd-year medical staff }\end{array}$ \\
\hline $\begin{array}{l}\text { Chai et al, } 2015 \\
\text { (United States) }\end{array}$ & Dermatology & Pilot/feasibility study & $\begin{array}{l}\text { Hospital - Emergency } \\
\text { department (urban } \\
\text { academic hospital) }\end{array}$ & $\begin{array}{l}\text { Allows teledermatolgosists to complete a } \\
\text { dermatology assessment via live video feed } \\
\text { after in-person consultation by a resident }\end{array}$ \\
\hline
\end{tabular}


Table 3. Summary of Google Glass approach as patient-centered interventions.

\begin{tabular}{lll}
\hline Source (health condition) & Purpose & Intervention description \\
\hline $\begin{array}{l}\text { Anam et al, } 2014 \\
\text { (Ophthalmology - visual impair- }\end{array}$ & $\begin{array}{l}\text { To allow people with vision impairments gain the ability } \\
\text { to determine non-verbal expressions }\end{array}$ & $\begin{array}{l}\text { Expression is the type of feature addition that is being } \\
\text { used }\end{array}$ \\
& & $\begin{array}{l}\text { It analyzes changes in facial expression and relays that } \\
\text { information in the form of captured frames to user }\end{array}$ \\
& $\begin{array}{l}\text { Helps user change their posture to better capture the facial } \\
\text { expression }\end{array}$
\end{tabular}

Garcia and Nahapetian, 2015

(Ophthalmology - visual impairment)

Pundlik et al, 2016

(Ophthalmology - visual impairment)

Hwang and Peli, 2016

(Ophthalmology - advanced agerelated macular degeneration)

Tanuwidjaja et al, 2014

(Ophthalmology - colorblind-

ness)

Lazewatsky et al, 2014

(Motor impairment)

Gips et al, 2015

(Motor impairment)

Sinyukov et al, 2016

To help patients have better control over their (Motor impairment - Locked-In wheelchairs

Syndrome)
To help guide people with visual impairments navigate indoor environments

To use vision magnification to aid in the completion of tasks

To augment the vision of the wearer so that they have improved vision

To help people with colorblindness see color

To show that GG can be used in conjunction with the PR2 robot to recognize people and objects and then manipulate the space around it

To help people operate a computer with only eye or head movements
Extract floor regions from images captured from GG to help guide the individual

An app is installed in GG that starts the camera and sends image frames to the mobile phone

An app is also installed that analyzes the floor plans and then sends it to the mobile phone through Bluetooth

Images that are captured contain the walls, floor, and ceiling

Leverages zoom capabilities of GG

Students are assigned tasks that involve the calculator and music player apps

Performance on these tasks is measured

Vision enhancement tool is added to GG

Participant wears GG which now warps the camera image to improve vision

Images that the vision enhancement tool sees are then relayed to user in real-time

Alters the way people perceive color

Applied Chroma, which is an app that detects color and relays that information to the participant

Implemented the Ishihara test, which tests for color vision deficiency

Implemented the Blackboard test that determines if a person can distinguish between green and orange

GG Bridge Node receives sensor data from GG and transmits it to Robots and Systems software (ROS) messages and publishes a coordinate frame for GG

ROS works with face detection; GG software also uses face detection and person recognition

Noggin software was developed to allow user to move a cursor across the screen through head movements

Noggin displays yes, no, and enter on the screen

Noggin uses the gyroscope to monitor head movements

GG Gab, another software, allows user to spell out a message

Patient uses the software installed on GG in conjunction with the motorized wheelchair

GG monitors facial expressions of the patient

GG's audio monitoring is used to understand voice commands and then relay the instructions to the motorized wheelchair 


\begin{tabular}{ll}
\hline Source (health condition) & Purpose \\
\hline $\begin{array}{l}\text { Malu and Findlater, 2015 } \\
\text { Motor impairment - upper }\end{array}$ & $\begin{array}{l}\text { To assess the accessibility of GG for individuals with } \\
\text { upper body motor impairments }\end{array}$
\end{tabular}

Intervention description

Using voice commands and the touchpad to go through day-to-day activities

Touchpad on GG was on the right arm of the device and senses taps and swipes through voice commands

Output is projected on the heads-up display

Participants completed tasks using swipes and tasks function

Participants then used a scale to rate the comport and ease of the touchpad and visual display

McNaney et al, 2014

(Motor impairment-Parkinson's Disease [PD])

McNaney et al, 2015

(Motor impairment - PD)

Zhao et al, 2016

(Motor impairment - PD)

Pervaiz and Patel, 2014

(Motor impairment - Dysarthria)

Miranda et al, 2014

(Psychological/Developmental SAD)

Voss et al, 2016

(Psychological/Developmental ASD)

Mirtchouk et al, 2016

(Eating monitoring)
To help people with PD counteract their symptoms by allowing them to carry out the normal functions of a mobile phone using voice commands, cueing for freezing gait

To help monitor speech loudness issues and provide feedback to help with self-management

To provide visual and auditory cues to aid in the modulation of gait

To help patients monitor their low volume in order to self-regulate and to provide clinicians with feedback to adjust therapy

To assess the feasibility of using GG to monitor blinking rates in individuals with social anxiety disorder
GG was used to manage social cues and alert the user

GG monitored movement and told the participant when they were freezing so that they could actively try to stop the behavior

Developed the LApp app that monitors loudness

Participants used the app for a set amount of time while carrying out a series of social interactions

Indicating when the volume was inappropriate so the user could adjust to hit the target loudness

GG was used to detect gait issues and improve them through cueing

Audiovisual cues were used, including a metronome, flashing light, optic flow, and a control (no cue)

Participants underwent a series of walking tasks and their gait was then analyzed for stability and freezing

Developed the SpeedOmeter software that compares vocal loudness to ambient noise

Provides feedback to user on their volume

System provides usage and performance history for user

Notifies patient of their volume so they can adjust

Monitor blinking behaviors

Used to gather data from the infrared (IR) sensor

The app dealt with IR data gathering, data processing, and HTTP communication

App processes the data and calculates when the user blinked

Participant uses GG to record everyday behaviors

Caregiver reviews system highlights and emotional moments so they are easily accessible for the reviewer

Caregivers can tag parts of the video that are especially important and add comments to the video

GG sensor was used to detect head movement that was specific to eating

Participants ate what they wanted and when they wanted and GG was supposed to detect when they were eating and for how long

Participants were allowed to do other activities when eating their meals 


\begin{tabular}{|c|c|c|}
\hline Source (health condition) & Purpose & Intervention description \\
\hline \multirow[t]{6}{*}{$\begin{array}{l}\text { Rahman et al, } 2015 \\
\text { (Eating monitoring) }\end{array}$} & \multirow[t]{6}{*}{ To detect a person's eating and drinking habits } & $\begin{array}{l}\text { Records a person's eating and drinking habits through } \\
\text { head movements }\end{array}$ \\
\hline & & Helps people with obesity and diabetes \\
\hline & & Developed the Glass Eating and Motion (GLEAM) dataset \\
\hline & & $\begin{array}{l}\text { Participants ate, walked, and did other activities during } \\
\text { the monitoring period }\end{array}$ \\
\hline & & Participants did not interact with GG but simply wore it \\
\hline & & GG sensors recorded movement \\
\hline \multirow[t]{2}{*}{$\begin{array}{l}\text { Ye et al, } 2015 \\
\text { (Eating monitoring) }\end{array}$} & \multirow[t]{2}{*}{ To detail eating habits to help weight reduction } & $\begin{array}{l}\text { Collects images of the person's day from their perspective } \\
\text { every } 30 \text { seconds }\end{array}$ \\
\hline & & $\begin{array}{l}\text { Amazon's Mechanical Turk is a human computation } \\
\text { platform that can determine eating behaviors and is used } \\
\text { to identify when a person is eating }\end{array}$ \\
\hline \multirow[t]{2}{*}{$\begin{array}{l}\text { Hernandez et al, } 2014 \\
\text { (Physiological measurements) }\end{array}$} & \multirow[t]{2}{*}{ To measure heart rate and breaths per minute } & $\begin{array}{l}\text { Participant would wear GG, and GG's accelerometer, } \\
\text { gyroscope, and camera were used to find user's pulse and } \\
\text { respiratory rates }\end{array}$ \\
\hline & & $\begin{array}{l}\text { The recording was done in several different positions in- } \\
\text { cluding, sitting, standing, and lying down }\end{array}$ \\
\hline \multirow{3}{*}{$\begin{array}{l}\text { Richer et al, } 2015 \\
\text { (Physiological measurements) }\end{array}$} & \multirow[t]{3}{*}{ To use the DailyHeart app to monitor ECGs } & GG presents ECG signals to user in everyday life \\
\hline & & $\begin{array}{l}\text { Signals are processed in real-time and classify the user's } \\
\text { heart beats }\end{array}$ \\
\hline & & It will store data in an internal database \\
\hline \multirow[t]{4}{*}{$\begin{array}{l}\text { Wiesner et al, } 2015 \\
\text { (Allergies) }\end{array}$} & \multirow[t]{4}{*}{$\begin{array}{l}\text { To give consumers information of possible allergens in } \\
\text { cosmetic products }\end{array}$} & $\begin{array}{l}\text { An app is developed for GG whose purpose is to scan } \\
\text { products }\end{array}$ \\
\hline & & $\begin{array}{l}\text { User scans the product in the store and the GG app iden- } \\
\text { tifies the product }\end{array}$ \\
\hline & & $\begin{array}{l}\text { User has uploaded the information of their specific aller- } \\
\text { gies and the app compares the ingredients to the user's } \\
\text { profile }\end{array}$ \\
\hline & & $\begin{array}{l}\text { GG indicates whether the user should buy the product } \\
\text { and why }\end{array}$ \\
\hline
\end{tabular}

\section{Description of Google Glass Use as Clinician-Centered Interventions}

Table 4 summarizes the Google Glass approach as clinician-centered interventions. Four of the clinician-focused studies $(4 / 30,13 \%)$ used Google Glass to assist in disaster relief by providing first responders with maps and navigational assistance [30], maintaining audiovisual communication with groups of paramedics and administrators [27], scanning triage tags [28], and performing teleconsultations with physician experts to confirm triage decisions [29]. Two studies $(2 / 30,7 \%)$ used Google Glass to help community health workers make more efficient diagnoses [32] and by allowing clinicians to retrieve images of similar cases [42]. Another (1/30, 3\%) provided nurses information about peripheral stimuli to help them more efficiently manage their clinical environment [33]. Two studies $(2 / 30,7 \%)$ used the teleconsultation capabilities of Google Glass to improve the accuracy of neurological [34] and emergency dermatology [56] examinations. Nine studies $(9 / 30,30 \%)$ used Google Glass in student training situations to provide first-person demonstrations of procedures [37], record students in simulated patient interactions $[38,49,52]$, enhance simulated interactions by projecting videos of the scenarios into their visual field $[35,48]$, provide students with live instruction from an expert $[40,46,55]$, and teach anatomy by providing real-time ultrasound imaging [47]. One study (1/30, 3\%) used Google Glass to provide patient monitoring data to assist anesthesiologists and minimize distractions during procedures [36]. Five studies $(5 / 30,17 \%)$ used Google Glass to capture images of X-rays $[39,44]$ and ECGs $[43,45]$ that physicians then interpreted for significant findings. One study $(1 / 30,3 \%)$ used Google Glass to minimize head movements during ultrasound-guided procedures by projecting the images onto Google Glass [41]. One study (1/30, 3\%) used Google Glass to take and analyze rapid diagnostic tests (RDTs) [50]. One study $(1 / 30,3 \%)$ helped clinicians evaluate burn patients by assisting in airway assessment [51]. One study $(1 / 30,3 \%)$ assessed the potential uses of Google Glass in autopsy or forensics settings by specifically evaluating the quality of images taken by Google Glass for documentation [53]. One study $(1 / 30,3 \%)$ leveraged multiple functions of Google Glass to assist with the treatment of chronic wounds [54]. Finally, one study (1/30, 3\%) developed an app for Google Glass to facilitate behavioral, cognitive, and social research [31]. 
Table 4. Summary of Google Glass approach as clinician-centered interventions.

\begin{tabular}{ll}
\hline Source (health condition) & Purpose \\
\hline $\begin{array}{l}\text { Gillis et al, 2015 } \\
\text { (Disaster relief) }\end{array}$ & $\begin{array}{l}\text { To provide a hands-free way for doctors to be updated } \\
\text { on the status and needed-care levels of critical-care pa- } \\
\text { tients }\end{array}$
\end{tabular}

Carenzo et al, 2014

(Disaster relief)

Cicero et al, 2014

(Disaster relief)

Newaz and Eide, 2015

(Disaster relief)

Paxton et al, 2015

(Behavioral sciences)

Pappachan et al, 2014

(Diagnostics)

Pascale et al, 2015

(Nursing - peripheral detection)

Yuan et al, 2015

(Neurology)

Chaballout et al, 2016

(Student training - health science students)

Drake-Brockman et al, 2016

(Anesthesiology)
To aid in nontechnical skills in the management of disasters and mass casualty incidents

To streamline the triage system and then also offer consultations from an expert physician to those onsite

To provide direction to first responders in a new area

To determine how interpersonal dynamics in conversation are affected by the environment

To assist community health workers to more efficiently diagnose patients

To help clinicians, such as nurses, pay attention to multiple patients while away from their station

To make a neurological examination as accurate as possible through collaboration

To teach health care students to respond to respiratory distress

To allow anesthesiologists to monitor vitals of patients during procedures
Intervention description

Developed a mesh network that covered a set area to allow communication between users and the hospital

Users wore GG and could communicate with each other across the lake

Users were then able to use the information they were getting in the field, record it, and relay it back to the hospital

Used an app to GG to guide a Simple Triage and Rapid Treatment Triage visually

Focused heavily on casualty identification, therefore the facial recognition capabilities for GG were used

Visual information was then relayed to a secondary location for others to monitor

Paramedics used GG to communicate with an offsite physician disaster expert

They assigned triage levels to victims using the SMART Triage System

Offsite physician had an audio-video interface with paramedics so they could be observed in the offsite location

One group used GG as a tool for navigation

The other group used a different device to navigate an unfamiliar neighborhood

The route was preset on GG or the other device

The app PsyGlass was created for GG

The students wore GG and were presented with a series of red or blue lights as well as audio stimuli

They had a conversation with the experimenter and their head movements were recorded through the GG accelerometer

Uses Rafiki, a GG software that calculates age and gender and other characteristics to diagnose a patient

Correlates between diseases, symptoms, and patients to determine the problem

Provided stimuli in the periphery of the nurses

GG was used to detect and notify the nurses when something was presented in their peripheral vision

A woman that suffered a right-sided dysphagia and asthenia was in the emergency department with a suspected stroke

A local physician lacking neurological knowledge used GG to establish a teleconsult with a remote specialist who guided the physician in evaluating the patient

Students watched a video while wearing GG

Video showed a patient in respiratory distress

Students then performed a procedure to aid respiratory distress on a manikin in front of them

AnaeVis was developed to run on GG, which provides visualization of patient monitoring data

Anesthetists wore the device while treating the patient and the signals were shown and recorded 


\begin{tabular}{ll}
\hline Source (health condition) & Purpose \\
\hline $\begin{array}{l}\text { Iversen et al, } 2015 \\
\begin{array}{l}\text { (Student training - physiothera- } \\
\text { py students) }\end{array}\end{array}$ & $\begin{array}{l}\text { To record } 1^{\text {st }} \text {-person view of procedures demonstrated } \\
\text { byctors to relay to students for training purposes }\end{array}$ \\
\hline
\end{tabular}

Son et al, 2015

To improve otolaryngology resident training by captur(Student training - otolaryngol- ing $1^{\text {st }}$-person recordings of clinic encounters for later ogy residents)

Spaedy et al, 2016

(Radiology)

Russel et al, 2014

(Student training - medical students [radiology])

Wu et al, 2014

(Student training - medical students and radiology residents)

Widmer et al, 2014

(Dermatology and Radiology)

Stetler et al, 2015

(Cardiology)

Duong et al, 2015

(Cardiology)

Jeroudi et al, 2014

(Cardiology)

Vallurupalli et al, 2013,

(Student training - medical students [cardiology]) evaluation

To improve the efficiency of remote chest X-ray interpretation

To determine if GG could provide telementoring instruction in bedside ultrasonography

To minimize the amount of distraction caused by monitors during ultrasounds

To improve diagnostics in dermatology and cardiology

To facilitate the interpretation of coronary angiograms

To facilitate the interpretation of ECGs

To improve resident training by streaming the view of residents during simulations to attending physicians for consultation
Intervention description

Faculty member wore GG during the performance of clinical skills

Video of clinical skill performance was then shown to students for the purpose of teaching

Residents were recorded in an outpatient clinic by patients

Patients were then given a survey to complete that rated their satisfaction level with their visit

Video information was evaluated by two different parties and a review was given back to residents

Fellows reviewed 12 chest X-rays with 23 major findings by viewing the image on GG, viewing an image taken by GG on a mobile device, and viewing the original X-ray on a desktop computer

One point was given for each major finding

Students wore GG and received real-time telementoring education

Telementoring was done by an expert at a different location

Students' goal was to obtain best parasternal long axis cardiac imaging using a portable GE Vscan

Medical practitioner wore the GG during the ultrasound procedure

GG screen projected images and video to the wearer

Practitioner's hand movements and eye movement were recorded to see if there was improvement

Participants would wear GG during a consultation

ParaDISE app was developed to be a medical image retrieval system

GG's visual and photo taking capabilities were utilized and then the photograph was sent into the interface and could be matched with similar images

Those similar images were then sent to the wearer

ECGs were selected that had important findings

GG zoom capabilities were used to identify each finding

Every time a participant identified a finding they received one point

ECGs were captured using the video function of GG specific finding

Students were then told to try to determine each of the findings in the angiograms

Physicians wore GG and looked at the ECG image on the screen

Physicians wore GG and viewed a photograph of the ECG taken using GG and then viewed on a mobile device

Results were then compared to other methods of viewing ECGs
Residents wore GG while working through four scenarios in cardiovascular practice

Live video of the scenarios taken by GG was streamed to a mobile phone or personal computer used by the attending physician 


\begin{tabular}{lll}
\hline Source (health condition) & Purpose & Intervention description \\
\hline $\begin{array}{l}\text { Benninger, 2015 } \\
\text { (Radiology) }\end{array}$ & To facilitate teaching anatomy to medical students & $\begin{array}{l}\text { Students familiarized themselves with GG for 10-30 min- } \\
\text { utes using a program called MiniGames } \\
\text { Students were then given tutorials in groups of 3-5 while } \\
\text { using GG with a finger probe to identify neuromuscular } \\
\text { and organ structures and spaces in the limbs and cavities } \\
\text { Students were tested during 7 separate laboratory examina- } \\
\text { tions over 1 year to identify the same structures and practice } \\
\text { procedures }\end{array}$ \\
&
\end{tabular}

Vaughn et al, 2016

(Student training - nursing students)

\section{Zahl et al, 2016}

(Student training - dental students)

Feng et al, 2015

(Diagnostics - HIV or cancer)

Spencer et al, 2014

(Pulmonology - airway assessment for burn victims)

Tully et al, 2015

(Student training - medical students [hospice])

Albrecht et al, 2014

(Pathology - autopsy and postmortem examinations)

Aldaz et al, 2015

(Chronic wounds)

Chai et al, 2015

(Toxicology)

Chai et al, 2014

(Dermatology)
To increase the perception of realism in nursing student simulations

To facilitate self- and peer-assessment of standardized patient (SP) interactions for dental students

To improve the efficiency of immunochromatographic diagnostic test analysis

To facilitate airway assessment of burn patients requiring surgery

To facilitate medical student self-evaluation after endof-life SP encounters

To evaluate the feasibility of using GG in a forensics setting

To facilitate photo documentation of chronic wounds for long-term care

To facilitate toxicology teleconsultation in the emergency department

To facilitate dermatology teleconsultation in the emergency department
Students were allowed 10 minutes to familiarize themselves with $\mathrm{GG}$ before the intervention

Students were then given the patient report and started the simulation in which GG projected a video of an acute asthma exacerbation scenario

1-2 Certified Healthcare Simulation Experts evaluated students' performance

3rd-year dental students volunteered to record their SP encounter using GG while a traditional static camera simultaneously recorded

All GG and static camera videos were later reviewed during Behavioral Patient Management small group discussions

Students rated how effective each type of video was for assessing communication skills

One or more RDTs, either HIV (qualitative) or PSA (quantitative), labeled with QR codes were imaged using GG

Images were automatically transmitted to a digital server that located all RDTs and produced a quantitative diagnostic result, which was reported to user

GG was worn by physicians during two cases of burn patients requiring airway assessment

Documentation of procedure by GG was evaluated after the intervention

2nd-year medical students participated in end-of-life SP encounters where the SP was wearing GG to record the encounter

Students then reviewed GG and traditional videos

Two physicians wore GG during 4 autopsy and postmortem examinations and took images using both GG and a traditional digital single lens reflex (DSLR) camera

Six forensic examiners evaluated the images for quality

Wound care nurses used SnapCap software on GG to take images, tag, and transfer them to patient electronic medical records

Image quality and ease of use were evaluated

Emergency medicine residents wore GG while evaluating poisoned patients

Real-time video of physician findings was transmitted to toxicology fellows and attendings for evaluation

Patients first had a standard dermatology consultation (phone call and sometimes a static photo of the rash) with a dermatology resident

Patients were then evaluated by the dermatology chief resident through a real-time video filmed by the patient (wearing GG) and viewed by the physician on a tablet 


\section{Feasibility and Acceptability of Google Glass as Patient-Centered Interventions}

Table 5 summarizes the user satisfaction results of the patient-centered interventions (see Multimedia Appendix 3 for more technical results). Overall, participant feedback on the comfort and ease of use of Google Glass in patient-centered interventions was very positive. Of the participants with visual impairments, Anam et al reported a median usability score of 4.6/5 [14], and Tanuwidjaja reported that a majority of participants believed the Google Glass intervention would be useful in everyday life [18]. Among the participants with motor impairments, namely Parkinson's Disease (PD), while overall reactions were positive [12] and some believed that Google Glass allowed them to do things they were not previously able to do independently [11], there were also some consistent frustrations expressed. For example, some experienced difficulties using the touchpad and voice navigation features as a result of tremors and dysarthria associated with the disease [10,11]. While participants with ASD reported positive experiences using Google Glass [20], participants using it to collect physiological data reported privacy concerns and found a smartwatch to have better usability [25]. Some of the common complaints reported were overheating of the device $[14,15,20]$, its relatively short battery life $[6,14,15,17,18,22,24]$, poor quality camera $[17,18]$, perceived stigma when wearing the device in public [14,25], wireless connectivity issues [26], and concerns about privacy and the protection of confidential information $[11,25]$. These results suggest the potential for future research and implementation to support patients if Google can address some of the device's technological limitations. However, the issues experienced by PD patients due to dysarthria and tremors should be addressed in interventions related to motor impairments.

Table 5. Feasibility and acceptability of Google Glass as patient-centered interventions.

\begin{tabular}{|c|c|}
\hline Source (health condition) & User satisfaction results \\
\hline Anam et al, 2014 & Participants completed 5-point Likert scale on usability of the Expression system (a score of 5=the best): \\
\hline (Ophthalmology - visual impairment) & $\begin{array}{l}\text { Learnability median 4.1, interquartile range (IQR) } 0.7 \text {; Informativeness median 4.5, IQR 1.0; Usability } \\
\text { median 4.6, IQR } 0.7 \text {; User Satisfaction median 4.5, IQR } 1.0 \text {; Willing to Use median 3.7, IQR 0.7. The } \\
\text { relatively low score for "Willing to Use" can be attributed to perceived uncertainty in social acceptability } \\
\text { of wearing a device such as GG. }\end{array}$ \\
\hline
\end{tabular}

Tanuwidjaja et al, 2014

(Ophthalmology - colorblindness)

Malu and Findlater, 2015

(Motor impairment - upper body)

McNaney et al, 2014

(Motor impairment - PD)

McNaney et al, 2015

(Motor impairment - PD)

Zhao et al, 2016

(Motor impairment - PD)

Voss et al, 2016

(Psychological/Developmental - ASD)

Richer et al, 2015

(Physiological measurements)
4/6 participants reported they found Chroma system useful in performing study tasks and would find it useful in everyday life. Two participants expressed concerns about system lag time in switching between modes. One participant did not find the system helpful because his vision test scores worsened when using Chroma.

Participants rated system features on a 5-point scale (1=very easy/comfortable to 5=very difficult/uncomfortable): Visual Display comfort median 2, mean 2.2, SD 1.2; ease median 2, mean 2.2, SD 1.2; Touchpad Gestures comfort median 3, mean 3, SD 2.2; ease median 2, mean 2.7, SD 1.9; Voice Commands ease median 1, mean 1.7, SD 1.2. For the reciprocal tapping task, most $(\mathrm{N}=8)$ found the large touchpad easiest to use, and most $(\mathrm{N}=7)$ found the large touchpad to be most physically comfortable.

Study exit interviews identified some concerns with usability of and patient satisfaction with GG. Some felt wearing GG in public drew unwanted attention, and 3/4 participants reported they would not wear GG in certain settings due to safety concerns. All participants experienced frustration when certain features, such as voice recognition and navigation, were difficult to use in everyday life or did not work. However, when the features were working properly, user satisfaction was high. GG enabled some to do things others without PD can do on mobile phones. Overall, reactions to GG were positive and showed appreciation for how GG could be used to help those with PD.

Study exit interviews revealed mixed reactions to LApp program, with some finding significant improvement in and confidence with their speech volume and others reporting the program performance was inconsistent. Additional frustrations were related to GG's short battery life and difficulties navigating the touchpad because of PD-related tremors.

Most users found GG easy or very easy to use $(\mathrm{N}=7 / 11)$ and the instructions on screen clear or very clear to read (9/12). One user particularly liked the bone-conducting headphone because the metronome was less audible to others around. Some participants disliked GG's placement of the visual display in the upper right corner $(n=3)$ and suggested images be projected binocularly $(n=1)$ or more focally $(n=2)$ in the visual field. They suggested verbal instructions $(n=9)$, rhythmic music $(n=2)$, and postural feedback $(n=1)$ as additional cues for the app and that cues be provided only when needed $(n=2)$.

Review of videos of participants using GG system at home showed that children reported positive experiences with the activities at home and stated they viewed the system as a toy. However, the device heated up to uncomfortable levels if worn too long.

Participants completed a qualitative assessment of their experience using DailyHeart on GG. Mean usability rating for smartwatches (4.2) was higher than GG rating (2.8). Almost a third of participants were afraid that health data stored in Google Fit could be misused by third parties. In comparing the use of DailyHeart on GG and on Android Wear, Wear outperformed GG on all measures (appearance, features, handling, distraction, and overall usability). 


\section{Feasibility and Acceptability of Google Glass as Clinician-Centered Interventions}

Table 6 summarizes user satisfaction and technical results of the clinician-centered interventions (see Multimedia Appendix 4 for more technical results). The clinician-centered studies, which also varied greatly in specializations and uses of Google Glass, reported more inconsistent reactions regarding the utility of the device. Many of the studies reported technical frustrations similar to those mentioned in the patient-centered interventions-specifically, short battery life [29,31,35,37,41,42,48,50,53], device overheating [31,35,37,41], difficulties with wireless network connection [29,35,37,41,42,48,55], and privacy concerns [28,31]. Multiple studies reported that, while the device was generally comfortable to wear and did not distract from the clinician's work, it did not significantly improve outcomes or the clinician's efficiency $[29,37,53]$. The main sources of frustration specific to clinician use were the size and quality of images taken with and viewed through the device $[42,45,50]$, difficulties in taking images and videos, and keeping patient monitors in the clinician's line of vision due to the fact that the Google Glass follows a person's head movements instead of gaze $[33,36,49]$. Specifically, Spaedy et al found that clinicians were dissatisfied viewing images of chest X-rays through Google Glass but were impressed with the images taken by the device and viewed on a mobile phone or computer [39]. In addition, Stetler et al, Duong et al, and Jeroudi et al reported that cardiologists were generally not confident with their interpretations of ECGs viewed through Google Glass [43-45]. However, other studies, in particular the ones that used Google Glass as a tool for training students, found that students had overall positive reactions to Google Glass and would recommend its future use [35,36,41,47-49,52]. For example, Chaballout et al found that most students $(10 / 12,83 \%)$ recommended its continued use in clinical simulations [35]. Similarly, Wu et al found that a majority (88\%) of the medical students and radiology residents would be likely to use ultrasound visualization through Glass instead of a traditional monitor [41]. One exception to this trend was a study by Iversen et al, which reported that a majority of the physiotherapy students $(26 / 39,67 \%)$ found Google Glass' video quality unacceptable, and many $(23 / 39,59 \%)$ did not feel the device enhanced their learning experience [37]. Despite this contradiction, these results suggest that the greatest potential for Google Glass implementation to support clinicians lies in student training. 
Table 6. Feasibility and acceptability of Google Glass as clinician-centered interventions.

\begin{tabular}{ll}
\hline Source (health condition) & User satisfaction results \\
\hline Cicero et al, 2014 & $\begin{array}{l}\text { First responders using GG completed a survey assessment after the intervention, and their responses } \\
\text { supported the idea that GG does not make a significant improvement in disaster triage. }\end{array}$
\end{tabular}

(Disaster relief)

Yuan et al, 2015

(Neurology)

Local physicians found that holding a mobile phone to provide the consulting specialist live images on GG was inconvenient.

Chaballout et al, 2016

(Student training - health science students)

Drake-Brockman et al, 2016

(Anesthesiology)

Iversen et al, 2015

(Student training - physiotherapy students)

Spaedy et al, 2016

(Radiology)

Wu et al, 2014

(Student training - medical students and radiology residents)

Stetler et al, 2015

(Cardiology)

Duong et al, 2015

(Cardiology)

Jeroudi et al, 2014

(Cardiology)

Benninger, 2015

(Radiology)

Vaughn et al, 2016

(Student training - nursing students)
Teleneurohospitalists using GG did not feel the system allows for patient evaluation similar to what would be achieved in-person.

Participants were asked to complete 2 post-intervention surveys, a 13-item Student Satisfaction and SelfConfidence in Learning Scale and a 20-item Simulation Design Scale (scale for both measures was $1=$ strongly disagree to $5=$ strongly agree). Most students recommended continued use of GG in clinical simulations $(\mathrm{N}=10 / 12)$. They also reported high mean scores on the simulations's design and satisfaction with the simulation to promote learning and self-confidence in learning.

Simulation Design Scale (mean [SD]): Objectives and information 4.65 (0.18); Support 4.85 (0.04); Problem solving 4.53 (0.30); Feedback/guided reflection 4.85 (0.14); Fidelity (realism) $4.67(0.12)$

Student Satisfaction and Self-Confidence with Learning (mean [SD]): Satisfaction with current learning 4.67 (0.13); Self-confidence in learning $4.35(0.60)$.

Anesthetists participating in the intervention were asked to complete a survey including a Likert scale and freeform questions: $78 \%$ would use GG again, $58 \%$ would recommend GG to colleagues, $21 \%$ felt GG improved patient management, $90 \%$ reported GG was comfortable to wear, $86 \%$ reported that information presented on GG was easy to read, $56 \%$ would wear GG in view of patients, $75 \%$ felt positive about using GG in the operating room environment, $82.5 \%$ reported that wearing GG did not distract from patient management.

Students who used GG in the study answered questions about the technology after the intervention. 67\% (26/39) of students evaluated GG video quality as not acceptable (score of $\leq 2$ on the Likert scale), and $59 \%(23 / 39)$ of students reported using GG did not enhance their learning experience.

Participants responded to a 5-point Likert scale about the quality of GG images and their confidence about their interpretation. When viewing images through GG, $87 \%(13 / 15)$ were dissatisfied with the image and unsure that such a small display would be able to provide the necessary level of detail. $80 \%(12 / 15)$ were impressed with image clarity taken via GG and viewed on the mobile device.

Participants who used GG responded to a post-exercise survey. 87\% reported GG was comfortable to use for ultrasound guidance. $88 \%$ reported they would be likely to use ultrasound visualization through GG as opposed to traditional monitors (18\% very likely, 35\% moderately likely, $35 \%$ somewhat likely). $78 \%$ indicated they would "very likely" be interested in future research studies involving GG in medical simulation and education.

Physicians responded to a 5-point user-experience Likert scale after the intervention. 58\% (7/12) were satisfied with GG image quality of ECGs. $50 \%(6 / 12)$ were confident in their interpretation when using GG.

Participants responded to a post-study survey regarding their satisfaction with image quality and comfort making clinical recommendations. 10\% (1/10) were "neutral" regarding quality and giving recommendations. $60 \%(6 / 10)$ of physicians were "somewhat satisfied" and would be "somewhat comfortable" giving recommendations. 30\% (3/10) were "very satisfied" and would be "very comfortable" giving recommendations.

Participants completed subjective ratings on a 5-point Likert scale regarding image quality and their confidence of ECG interpretation. 75\% (9/12) were dissatisfied with the ECG image quality when viewing via GG. $83 \%$ (10/12) were not confident in their interpretation when viewing via GG. 58\% (7/12) were neutral about ECG images taken by GG and viewed on mobile phones. 58\% (7/12) were more confident in their interpretation when viewing the GG image on a mobile phone than when viewing via GG.

Participants responded to a 5-point Likert scale questionnaire. Did they enjoy the exposure to technology applying the triple feedback method? Average score 4.6. Would they prefer more time with the technology? Average score 4.8

After the intervention, students responded to 2 surveys, the Simulation Design Scale and the Self-Confidence in Learning Scale (both 5-point scales from $1=$ strongly disagree to $5=$ strongly agree), to assess their perception of GG in the simulation: Independent problem-solving was facilitated, 4.75 (0.45); Resembled a real-life situation, $4.75(0.45)$; Teaching methods were helpful and effective, $4.67(0.65)$; Teaching materials were motivating and helpful, 4.58 (0.90); Confidence in mastering simulation content: 4.42 (0.51); Develops skills/knowledge applicable to a clinical setting, $4.83(0.39)$ 


\begin{tabular}{|c|c|}
\hline Source (health condition) & User satisfaction results \\
\hline $\begin{array}{l}\text { Zahl et al, } 2016 \\
\text { (Student training - dental students) }\end{array}$ & $\begin{array}{l}\text { Students responded to } 4 \text { open- and closed-text items about using GG and static video for self- and peer- } \\
\text { assessment. Students' reported mean score was higher for GG recordings ( } 84.61) \text { than static video (79.74). } \\
\text { Students reported that verbal communication was more easily assessed by reviewing GG video (23.87) } \\
\text { than static video ( } 22.17) \text {; paraverbal communication was more easily assessed by reviewing GG video } \\
\text { (24.26) than static video ( } 21.51) \text {; and nonverbal communication was more easily assessed by reviewing } \\
\text { static video (19.78) than GG video (17.09). }\end{array}$ \\
\hline
\end{tabular}

Tully et al, 2015

(Student training - medical students [hospice])

\begin{abstract}
Albrecht et al, 2014
(Pathology - autopsy and postmortem examinations)
\end{abstract}

Chai et al, 2015

(Toxicology)

Chai et al, 2014

(Dermatology)

Students responded to a 5-point Likert scale on how distracting they found GG during the intervention. $23 \%$ (7/30) reported a "positive, nondistracting experience." 37\% (11/30) reported a "positive, initially distracting experience." 17\% (5/30) reported a "neutral experience." 10\% (3/30) reported a "negative experience." After reviewing the videos filmed with GG, 70\% (16/30) believed that GG is worth including in the clinical skills training program.

Both participants agreed that GG was comfortable to wear but required more physical effort to capture images than a DSLR camera.

Study participants completed a survey immediately after the consult about their experience viewing a teleconsult through GG: $94 \%$ (17/18) were confident in the toxidrome after GG consultation as compared to $56 \%(10 / 18)$ who were confident after phone consultation.

All participants responded to a survey on acceptability of GG after their consultation. 93.5\% (29/31) were overall satisfied with the video consultation. $22.6 \%$ (7/31) preferred care provided through mobile video communication technology over a standard face-to-face clinic visit. 74.2\% (23/31) preferred care provided through mobile video communication technology over standard emergency department telephone consultation. $93.3 \%$ (28/31) would recommend the video consultation to others. $96.8 \%$ (28/30) felt comfortable that privacy was protected during the video encounter. $96.8 \%(30 / 31)$ were confident in the video equipment used.

\section{Discussion}

\section{Principal Findings}

In recent years, wearable devices such as wrist-worn accelerometers and head-mounted devices have become increasingly popular for their applications to everyday life as well as to various industries. While Google Glass, one of the more well-known head-mounted wearable devices, has yet to successfully break into the consumer market, various industries are eager to harness its potential in their fields. Medicine is one such industry; however, far greater attention has been paid to surgical applications than to nonsurgical ones. In this systematic review, we assessed existing evidence of the usability, benefits, and limitations of Google Glass to support both patients and clinicians in nonsurgical medical settings. Overall, the evidence was somewhat limited by a small number of studies fitting all inclusion criteria, small sample sizes, and other methodological considerations, particularly for statistical analysis. We included 51 studies that met our pre-set inclusion criteria, with the majority of studies describing clinician-centered interventions. There was a wide range of health conditions and uses of Google Glass. While information regarding age of participants was limited, the studies that did include age information were conducted with adults and none within pediatric populations. Many were conducted in laboratory, hospital, and student training settings, which indicates potential of university-affiliated teaching hospitals to integrate wearable technologies to make clinicians more efficient and provide clinical support to patients.

Unlike our systematic review, other recent reviews of the use of wearable technology in medicine included other heads-up devices besides Google Glass and did not distinguish between surgical and nonsurgical interventions $[3,4]$. Some of the uses of Google Glass in these studies include data visualization and video recording during surgery and interventional radiology, smart checklists, telementoring, virtual reality for education or pain management, interpretation of images, teleconsultation, teleconferencing, drug delivery tracking, patient empowerment, laboratory diagnostics, and forensic medicine [3,4].

A recent systematic review of medical applications of Google Glass in both surgical and nonsurgical settings found more globally positive support for the technology's use in these settings [4]. However, this systematic review discussed a smaller sample of articles $(n=21)$ that spanned surgical and nonsurgical medical interventions as well as scientific settings in general. Furthermore, original research studies on Google Glass in surgical interventions report fewer technical issues with the device and recommend strategies to overcome those that were encountered. One study, in which a pediatric surgeon wore Google Glass continuously for 4 weeks, reports with confidence that the photographic and video quality of the device was sufficient to capture all clinically relevant findings [57]. In contrast, many of the studies included in our analysis cited the photographic and video quality of Glass as a significant clinical limitation. While our findings regarding the limitations to the use of Glass, namely battery life, photographic and video quality, and streaming capabilities, were consistent with those encountered in surgical applications, the surgical studies seem to have made more progress in testing potential solutions. For example, one plastic surgeon used a USB-powered pocket battery to eliminate the need to recharge the device during the operation, noise-canceling headphones to enhance the sound transmitted by Glass, and a light emitting diode (LED) lamp headset to improve photo and video quality [4]. These findings support the potential of Google Glass to be even more beneficial in nonsurgical medical interventions if technical limitations are 
overcome either in newer models of the device or with the implementation of these solutions.

\section{Strengths and Limitations}

Our systematic review has a number of strengths. First, our review was conducted following the recommendations and guidelines for rigorous systematic reviews methodology [58-60]. Second, we used a very sensitive search strategy guided by a librarian information specialist with no language restrictions to include as many relevant studies as possible and minimize possible publication bias. In addition, we searched other resources, including published systematic reviews, clinical trial registries, and different electronic databases. Finally, 2 authors completed the review process independently at all stages.

Our systematic review of the literature has some potential methodological limitations. First, similar to other systematic reviews, although our search criteria were comprehensive, we could have missed some relevant articles [61]. Second, we included only original research papers that have been published in peer-reviewed journals, and the possibility of publication bias with the tendency to report positive study results cannot be excluded [62]. Finally, a number of the studies included in our review had a relatively small sample size.

\section{Conclusions}

Results regarding the feasibility, usability, and acceptability of Google Glass in nonsurgical medical settings were extremely varied, with more positive results being reported for patient-centered studies and student training settings. Further investigation with rigorous research designs evaluating the efficacy and cost-effectiveness of these more successful interventions in supporting patients and clinicians is warranted. These efforts would be beneficial in informing the base of evidence on the use of wearable devices, such as Google Glass, in medicine.

\section{Acknowledgments}

We thank Ms Linda O’Dwyer (Galter Health Sciences Library, Northwestern University Feinberg School of Medicine, Chicago, IL) for her support with the literature search. We also thank Ms Ayana Ceaser (Northwestern University Weinberg College of Arts and Sciences, Evanston, IL) for her help with data extraction.

\section{Conflicts of Interest}

None declared.

\section{Multimedia Appendix 1 \\ PRISMA checklist.}

\section{[PDF File (Adobe PDF File), 65KB-Multimedia Appendix 1]}

\section{Multimedia Appendix 2}

Search strategies.

[PDF File (Adobe PDF File), 27KB-Multimedia Appendix 2]

\section{Multimedia Appendix 3}

Summary of the technical results of the patient-centered studies.

[PDF File (Adobe PDF File), 80KB-Multimedia Appendix 3]

\section{Multimedia Appendix 4}

Summary of the technical results of the clinician-centered studies.

[PDF File (Adobe PDF File), 94KB-Multimedia Appendix 4]

\section{References}

1. Iqbal MH, Aydin A, Brunckhorst O, Dasgupta P, Ahmed K. A review of wearable technology in medicine. J R Soc Med 2016 Oct;109(10):372-380. [doi: 10.1177/0141076816663560] [Medline: 27729595]

2. Michael A, Tehrani K. Wearable Technology and Wearable Devices: Everything You Need to Know. 2014. URL: http:/ /www.wearabledevices.com/what-is-a-wearable-device/ [accessed 2017-08-27] [WebCite Cache ID 6t1sQoa7o]

3. Wrzesinska N. MEDtube Science. The use of smart glasses in healthcare URL: https://medtube.net/science/wp-content/ uploads/2014/03/The-use-of-smart-glasses-in-healthcare-\%E2\%80\%93-review.pdf [accessed 2017-08-27] [WebCite Cache ID 6t1sqqx1p] 
4. Davis CR, Rosenfield LK. Looking at plastic surgery through Google Glass: part 1. Systematic review of Google Glass evidence and the first plastic surgical procedures. Plast Reconstr Surg 2015 Mar;135(3):918-928. [doi: 10.1097/PRS.0000000000001056] [Medline: 25719707]

5. Moher D, Liberati A, Tetzlaff J, Altman DG, PRISMA Group. Preferred reporting items for systematic reviews and meta-analyses: the PRISMA statement. J Clin Epidemiol 2009 Oct;62(10):1006-1012. [doi: 10.1016/j.jclinepi.2009.06.005] [Medline: 19631508$]$

6. Lazewatsky D, Bowie C, LaFortune J. Wearable computing to enable robot microinteractions. 2014 Presented at: International Symposium on Robot and Human Interactive Communication; Aug 25-29, 2014; Edinburgh, UK p. 141-146 URL: http:/ /ieeexplore.ieee.org:80/document/6926244/?reload=true

7. Gips J, Zhang M, Anderson D. Towards a Google Glass Based Head Control Communication System for People with Disabilities. In: Intephanidis C, editor. Communications in Computer and Information Science. Switzerland: Springer International Publishing; Jul 12, 2015:978-983.

8. Sinyukov D, NW RT. Augmenting a voice and facial expression control of a robotic wheelchair with assistive navigation. 2014 Presented at: International Conference on Systems, Man and Cybernetics (SMC); Oct 5-8, 2014; San Diego, CA p. 1088-1094 URL: https://doi.org/10.1109/SMC.2014.6974059

9. Malu M, Findlater L. Personalized, Wearable Control of a Head-mounted Display for Users with Upper Body Motor Impairments. 2015 Presented at: Annual ACM Conference on Human Factors in Computing Systems; Apr 18-23, 2015; Seoul, Republic of Korea p. 221-230 URL: https://doi.org/10.1145/2702123.2702188 [doi: 10.1145/2702123.2702188]

10. McNaney R, Poliakov I, Vines J, Balaam M, Zhang P, Olivier P. LApp: A Speech Loudness Application for People with Parkinson's on Google Glass. 2015 Presented at: Annual ACM Conference on Human Factors in Computing Systems; Apr 18-23, 2015; Seoul, Republic of Korea p. 497-500 URL: https://doi.org/10.1145/2702123.2702292

11. McNaney R, Vines J, Roggen D, Balaam M, Zhang P, Poliakov I, et al. Exploring the acceptability of google glass as an everyday assistive device for people with parkinson's. 2014 Presented at: SIGCHI Conference on Human Factors in Computing Systems; Apr. 26-May 1, 2014; Toronto, Ontario, Canada p. 2551-2554 URL: https://dl.acm.org/citation. cfm?id=2557092 [doi: $10.1145 / 2556288.2557152]$

12. Zhao Y, Nonnekes J, Storcken EJM, Janssen S, van WEEH, Bloem BR, et al. Feasibility of external rhythmic cueing with the Google Glass for improving gait in people with Parkinson's disease. J Neurol 2016 Jun;263(6):1156-1165 [FREE Full text] [doi: 10.1007/s00415-016-8115-2] [Medline: 27113598]

13. Pervaiz M, Patel R. SpeechOmeter: heads-up monitoring to improve speech clarity. 2014 Presented at: International ACM SIGACCESS Conference on Computers \& Accessibility; Oct 20-22, 2014; Rochester, New York p. 319-320 URL: https:/ /doi.org/10.1145/2661334.2661339

14. Anam A, Alam S, Yeasin M. Expression: A Dyadic Conversation Aid using Google Glass for People with Visual Impairments. 2014 Presented at: International Conference on Mobile Computing, Applications and Services (MobiCASE); Nov. 6-7, 2014; Austin, TX p. 211-214 URL: https://doi.org/10.4108/icst.mobicase.2014.257780

15. Garcia G, Nahapetian A. Wearable computing for image-based indoor navigation of the visually impaired. In: Wireless Health Conference. 2015 Presented at: Wireless Health; Oct 14-16, 2015; Bethesda, MD p. 6. [doi: 10.1145/2811780.2811959]

16. Pundlik S, HuaQi Y, Rui L, Peli E, Gang L. Magnifying Smartphone Screen Using Google Glass for Low-Vision Users. IEEE Trans Neural Syst Rehabil Eng 2017 Jan;25(1):52-61. [doi: 10.1109/TNSRE.2016.2546062] [Medline: 28113862]

17. Hwang AD, Peli E. An augmented-reality edge enhancement application for Google Glass. Optom Vis Sci 2014 Aug;91(8):1021-1030 [FREE Full text] [doi: 10.1097/OPX.0000000000000326] [Medline: 24978871]

18. Tanuwidjaja ED, Koa KC, Shao CPCN. Chroma: A Wearable Augmented-Reality Solution for Color-Blindness. 2014 Presented at: UbiComp; Sept. 13-17, 2017; Seattle, WA p. 799-810 URL: http://ubicomp.org/ubicomp2014/ [doi: $10.1145 / 2632048.2632091]$

19. Miranda D, Calderón M, Favela J. Anxiety detection using wearable monitoring. 2014 Presented at: MexIHC; Nov. 3-5, 2014; Oaxaca, Mexico p. 34-41 URL: http://www.mexihc.org/2014/EN [doi: 10.1145/2676690.2676694]

20. Voss C, Washington P, Haber N. Superpower glass: delivering unobtrusive real-time social cues in wearable systems. 2016 Presented at: UbiComp; Nov. 12-16, 2016; Heidelberg, Germany p. 1218-1226 URL: http://ubicomp.org/ubicomp2016/ [doi: $\underline{10.1145 / 2968219.2968310]}$

21. Mirtchouk M, Merck C, Kleinberg S. Automated estimation of food type and amount consumed from body-worn audio and motion sensors. 2016 Presented at: UbiComp; Sept. 12-16, 2016; Heidelberg, Germany p. 451-462 URL: http://ubicomp. org/ubicomp2016/ [doi: 10.1145/2494091.2494143]

22. Rahman S, Merk C, Huang Y, Kleinberg S. Unintrusive Eating Recognition using Google Glass. 2015 Presented at: PervasiveHealth; May 20-23, 2015; Istanbul, Turkey p. 108-111 URL: http://pervasivehealth.org/2015/show/home [doi: 10.4108/icst.pervasivehealth.2014.255423]

23. Ye X, Chen G, Cao Y. Automatic Eating Detection using head-mount and wrist-worn accelerometers. : IEEE; 2015 Presented at: International Conference on E-health Networking, Application \& Services (HealthCom); Oct. 14-17, 2015; Boston, MA p. 578-581. [doi: 10.1109/HealthCom.2015.7454568] 
24. Hernandez J, Li Y, Rehag JM, Picard RW. BioGlass: Physiological Parameter Estimation Using a Head-mounted Wearable Device. EAI International Conference on. 2014 Presented at: International Conference on Wireless Mobile Communication and Healthcare (Mobihealth); Nov. 3-5, 2014; Athens, Greece URL: https://doi.org/10.1109/MOBIHEALTH.2014.7015908

25. Richer R, Maiwald T, Pasluosta C, Hensel B, Eskofier B. Novel human computer interaction principles for cardiac feedback using google glass and Android wear. 2015 Presented at: International Conference on Wearable and Implantable Body Sensor Networks (BSN); June 9-12, 2015; Cambridge, MA p. 1-6. [doi: 10.1109/BSN.2015.7299363]

26. Wiesner M, Pobiruchin M, Hetterich C, Pfeifer D. GlassAllergy: a Google Glass-based solution to empower patients with skin allergies. Stud Health Technol Inform 2014;205:548-552. [Medline: 25160245]

27. Gillis J, Calyam P, Bartels A. Panacea's Glass: Mobile Cloud Framework for Communication in Mass Casualty Disaster Triage. 2015 Presented at: International Conference on Mobile Cloud Computing, Services, and Engineering (MobileCloud); Mar. 30-Apr. 3, 2015; San Francisco, CA p. 128-134 URL: https://doi.org/10.1109/MobileCloud.2015.39

28. Carenzo L, Barra FL, Ingrassia PL, Colombo D, Costa A, Della CF. Disaster medicine through Google Glass. Eur J Emerg Med 2015 Jun;22(3):222-225. [doi: 10.1097/MEJ.0000000000000229] [Medline: 25460812]

29. Cicero MX, Walsh B, Solad Y, Whitfill T, Paesano G, Kim K, et al. Do you see what I see? Insights from using google glass for disaster telemedicine triage. Prehosp Disaster Med 2015 Feb;30(1):4-8. [doi: 10.1017/S1049023X1400140X] [Medline: 25571779]

30. Newaz F, Eide A, Pultier A. Supporting first responder in-field communication and navigation using head-mounted displays. 2015 Presented at: International Conference on Information Systems for Crisis Response and Management (ISCRAM); May 24-27, 2015; Kristiansand, Norway URL: http://idl.iscram.org/files/fahdbinmaleknewaz/2015/ 1208 FahdBinMalekNewaz etal2015.pdf

31. Paxton A, Rodriguez K, Dale R. PsyGlass: Capitalizing on Google Glass for naturalistic data collection. Behav Res Methods 2015 Sep;47(3):608-619. [doi: 10.3758/s13428-015-0586-z] [Medline: 25893865]

32. Pappachan P, Yus R, Joshi A, Finin T. Rafiki: A Semantic and Collaborative Approach to Community Health-Care in Underserved Areas. 2014 Presented at: International Conference on Collaborative Computing: Networking, Applications and Worksharing (CollaborateCom); Oct. 22-25, 2014; Miami, FL URL: https://doi.org/10.4108/icst.collaboratecom.2014. $\underline{257299}$ [doi: $10.4108 /$ icst.collaboratecom.2014.257299]

33. Pascale M, Sanderson P, Liu D, Mohamed I, Stigter N, Loeb R. Peripheral Detection for Abrupt Onset Stimuli Presented via Head-Worn Display. Proceedings of the Human Factors and Ergonomics Society Annual Meeting 2015;59(1):1326-1330 [FREE Full text]

34. Yuan Z, Liu Z, Wei D, Shi M, Wang B, Liu Y, et al. Mobile Stroke: An Experience of Intravenous Thrombolysis Guided by Teleconsultation Based on Google Glass. CNS Neurosci Ther 2015 Jul;21(7):607-609. [doi: 10.1111/cns.12413] [Medline: 26096048]

35. Chaballout B, Molloy M, Vaughn J, Brisson IR, Shaw R. Feasibility of Augmented Reality in Clinical Simulations: Using Google Glass With Manikins. JMIR Med Educ 2016 Mar 07;2(1):e2 [FREE Full text] [doi: 10.2196/mededu.5159] [Medline: 27731862]

36. Drake-Brockman TFE, Datta A, von UBS. Patient monitoring with Google Glass: a pilot study of a novel monitoring technology. Paediatr Anaesth 2016 May;26(5):539-546. [doi: 10.1111/pan.12879] [Medline: 26992465]

37. Iversen M, Kiami S, Singh K, Masiello I, von Heideken HJ. Prospective, randomised controlled trial to evaluate the effect of smart glasses on vestibular examination skills. BMJ Innovations 2016;2:99-105 [FREE Full text] [doi: 10.1136/bmjinnov-2015-000094]

38. Son E, Halbert A, Abreu S, Hester R, Jefferson G, Jennings K, et al. Role of Google Glass in improving patient satisfaction for otolaryngology residents: a pilot study. Clin Otolaryngol 2017 Apr;42(2):433-438. [doi: 10.1111/coa.12810] [Medline: 27992944]

39. Spaedy E, Christakopoulos GE, Tarar MNJ, Christopoulos G, Rangan BV, Roesle M, et al. Accuracy of remote chest X-ray interpretation using Google Glass technology. Int J Cardiol 2016 Sep 15;219:38-40. [doi: 10.1016/j.ijcard.2016.05.070] [Medline: 27262231]

40. Russell PM, Mallin M, Youngquist ST, Cotton J, Aboul-Hosn N, Dawson M. First "glass" education: telementored cardiac ultrasonography using Google Glass - a pilot study. Acad Emerg Med 2014 Nov;21(11):1297-1299 [FREE Full text] [doi: 10.1111/acem.12504] [Medline: 25377415]

41. Wu TS, Dameff CJ, Tully JL. Ultrasound-guided central venous access using Google Glass. J Emerg Med 2014 Dec;47(6):668-675. [doi: 10.1016/j.jemermed.2014.07.045] [Medline: 25281180]

42. Widmer A, Schaer R, Markonis D, Muller H. Facilitating medical information search using Google Glass connected to a content-based medical image retrieval system. Conf Proc IEEE Eng Med Biol Soc 2014;2014:4507-4510. [doi: 10.1109/EMBC.2014.6944625] [Medline: 25570993]

43. Stetler J, Resendes E, Martinez-Parachini JR, Patel K, Amsavelu S, Tarar MNJ, et al. Hands-free zoom and pan technology improves the accuracy of remote electrocardiogram interpretation using Google Glass. Int J Cardiol 2016 Feb 01;204:147-148. [doi: 10.1016/j.ijcard.2015.11.144] [Medline: 26657610] 
44. Duong T, Wosik J, Christakopoulos GE, Martínez Parachini JR, Karatasakis A, Tarar MNJ, et al. Interpretation of Coronary Angiograms Recorded Using Google Glass: A Comparative Analysis. J Invasive Cardiol 2015 Oct;27(10):443-446 [FREE Full text] [Medline: 26429845]

45. Jeroudi OM, Christakopoulos G, Christopoulos G, Kotsia A, Kypreos MA, Rangan BV, et al. Accuracy of remote electrocardiogram interpretation with the use of Google Glass technology. Am J Cardiol 2015 Feb 01;115(3):374-377. [doi: 10.1016/j.amjcard.2014.11.008] [Medline: 25482681]

46. Vallurupalli S, Paydak H, Agarwal SK, Agrawal M, Assad-Kottner C. Wearable technology to improve education and patient outcomes in a cardiology fellowship program - a feasibility study. Health Technol 2013 Oct 11;3(4):267-270. [doi: $10.1007 / \mathrm{s} 12553-013-0065-4]$

47. Benninger B. Google Glass, ultrasound and palpation: the anatomy teacher of the future? Clin Anat 2015 Mar;28(2):152-155. [doi: 10.1002/ca.22480] [Medline: 25377631]

48. Vaughn J, Lister M, Shaw RJ. Piloting Augmented Reality Technology to Enhance Realism in Clinical Simulation. Comput Inform Nurs 2016 Sep;34(9):402-405. [doi: 10.1097/CIN.0000000000000251] [Medline: 27258807]

49. Zahl DA, Schrader SM, Edwards PC. Student perspectives on using egocentric video recorded by smart glasses to assess communicative and clinical skills with standardised patients. Eur J Dent Educ 2016 Jul 06. [doi: 10.1111/eje.12217] [Medline: 27380732]

50. Feng S, Caire R, Cortazar B, Turan M, Wong A, Ozcan A. Immunochromatographic diagnostic test analysis using Google Glass. ACS Nano 2014 Mar 25;8(3):3069-3079 [FREE Full text] [doi: 10.1021/nn500614k] [Medline: 24571349]

51. Spencer RJ, Chang PH, Guimaraes AR, Firth PG. The use of Google Glass for airway assessment and management. Paediatr Anaesth 2014 Sep;24(9):1009-1011. [doi: 10.1111/pan.12496] [Medline: 25039494]

52. Tully J, Dameff C, Kaib S, Moffitt M. Recording medical students' encounters with standardized patients using Google Glass: providing end-of-life clinical education. Acad Med 2015 Mar;90(3):314-316. [doi: 10.1097/ACM.0000000000000620] [Medline: 25551855]

53. Albrecht U, von JU, Kuebler J, Zoeller C, Lacher M, Muensterer OJ, et al. Google Glass for documentation of medical findings: evaluation in forensic medicine. J Med Internet Res 2014 Feb 12;16(2):e53 [FREE Full text] [doi: 10.2196/jmir.3225] [Medline: 24521935]

54. Aldaz G, Shluzas LA, Pickham D, Eris O, Sadler J, Joshi S, et al. Hands-free image capture, data tagging and transfer using Google Glass: a pilot study for improved wound care management. PLoS One 2015;10(4):e0121179 [FREE Full text] [doi: 10.1371/journal.pone.0121179] [Medline: 25902061]

55. Chai PR, Babu KM, Boyer EW. The Feasibility and Acceptability of Google Glass for Teletoxicology Consults. J Med Toxicol 2015 Sep;11(3):283-287 [FREE Full text] [doi: 10.1007/s13181-015-0495-7] [Medline: 26245879]

56. Chai PR, Wu RY, Ranney ML, Bird J, Chai S, Zink B, et al. Feasibility and Acceptability of Google Glass for Emergency Department Dermatology Consultations. JAMA Dermatol 2015 Jul;151(7):794-796. [doi: 10.1001/jamadermatol.2015.0248] [Medline: 25874898]

57. Muensterer OJ, Lacher M, Zoeller C, Bronstein M, Kübler J. Google Glass in pediatric surgery: an exploratory study. Int J Surg 2014;12(4):281-289 [FREE Full text] [doi: 10.1016/j.ijsu.2014.02.003] [Medline: 24534776]

58. Moher D, Shamseer L, Clarke M, Ghersi D, Liberati A, Petticrew M, et al. Preferred reporting items for systematic review and meta-analysis protocols (PRISMA-P) 2015 statement. Syst Rev 2015 Jan;4:1 [FREE Full text] [doi:

10.1186/2046-4053-4-1] [Medline: 25554246]

59. Centre for Reviews and Dissemination. Systematic Reviews: CRD's Guidance for Undertaking Reviews in Health Care (Internet). York, UK; 2009. URL: https://www.york.ac.uk/media/crd/Systematic Reviews.pdf[WebCite Cache ID 6pJ0smh62]

60. Higgins JPT, Green S. The Cochrane Collaboration. 2011. URL: http://www.cochrane-handbook.org[WebCite Cache ID 6pIyMSTKD]

61. Bartolucci AW. Overview, strengths, limitations of systematic reviews and meta-analyses. In: Chiappelli F, editor. Evidence-Based Practice: Toward Optimizing Clinical Outcomes. Berlin, Germany: Springer-Verlag; 2010:34.

62. Dubben H, Beck-Bornholdt H. Systematic review of publication bias in studies on publication bias. BMJ 2005 Aug 20;331(7514):433-434 [FREE Full text] [doi: 10.1136/bmj.38478.497164.F7] [Medline: 15937056]

\section{Abbreviations}

ASD: autism spectrum disorder

ECG: electrocardiogram

GG: Google Glass

PD: Parkinson's Disease

RDT: rapid diagnostic test

SAD: social anxiety disorder

SP: standardized patient 
Edited by G Eysenbach; submitted 08.08.17; peer-reviewed by N Shah, UV Albrecht; comments to author 24.08.17; revised version received 28.08.17; accepted 28.08.17; published 19.10 .17

Please cite as:

Dougherty B, Badawy SM

Using Google Glass in Nonsurgical Medical Settings: Systematic Review

JMIR Mhealth Uhealth 2017;5(10):e159

URL: http://mhealth.jmir.org/2017/10/e159/

doi: $10.2196 /$ mhealth.8671

PMID: 29051136

CBryn Dougherty, Sherif M Badawy. Originally published in JMIR Mhealth and Uhealth (http://mhealth.jmir.org), 19.10.2017. This is an open-access article distributed under the terms of the Creative Commons Attribution License (https://creativecommons.org/licenses/by/4.0/), which permits unrestricted use, distribution, and reproduction in any medium, provided the original work, first published in JMIR mhealth and uhealth, is properly cited. The complete bibliographic information, a link to the original publication on http://mhealth.jmir.org/, as well as this copyright and license information must be included. 